\title{
Interação colaborativa na graduação em língua francesa: uma experiência de educação online em tempos pandêmicos
}

\author{
Collaborative Interaction in French Language \\ Undergraduates: An Online Education Experience in \\ Pandemic Times
} Interaction collaborative dans la licence de Lettres Français: une expérience d'éducation en ligne en temps de pandémie

\author{
Maria del Carmen de la Torre Aranda
}

\section{RESUMO}

Este artigo tem por objetivo apresentar e discutir usos e práticas de linguagem que promoveram a participação e a interação colaborativa entre estudantes de graduação em plataforma usada para a educação online. As práticas de aprendizagem se realizaram no contexto de uma disciplina de morfossintaxe do francês para a graduação em Letras Francês da Universidade de Brasilia, durante o periodo de ensino remoto decorrente do cenário da pandemia em 2020. Apoiadas nas noções de mediação pelo texto e de aprendizagem/interação colaborativa (WARSCHAUER, 1997; ZOUROU, 2007; BRAGA, 2013), as práticas tiveram por objetivo proporcionar uma aprendizagem da língua e sobre

1. Universidade de Brasília - UnB. Brasília - Brasil. https://orcid.org/0000-0002-79006362. E-mail: mariadelcarmen@unb.br. 
a língua francesa tomando como recurso textual de reflexão o próprio material linguístico-discursivo construído pelos estudantes em suas interações no ambiente online. Narrativas dos estudantes indicam que a perspectiva da educação online adotada favorece o enfoque pedagógico na negociação de sentidos colaborativamente, ao mesmo tempo que abre espaço a um trabalho crítico sobre a linguagem e os processos de elaboração de sentidos em ambientes online.

Palavras-chave: interação colaborativa; educação em línguas; tecnologia digital, mediação docente.

\begin{abstract}
This article aims to present and discuss language uses and practices that have promoted participation and collaborative interaction among undergraduate students in a platform used for online education. The learning practices took place in the context of a French morphosyntax course for the Undergraduate Program in French Language Studies at Universidade de Brasilia, during the remote teaching period arising from the pandemic scenario in 2020. Supported by the notions of text mediated learning and collaborative interaction (WARSCHAUER, 1997; ZOUROU, 2007; BRAGA, 2013), the practices aimed to provide learning the language and about the language, taking as a textual resource for reflection the very linguistic-discursive material constructed by the students in their interactions in the online environment. The students' narratives indicate that the adopted online education perspective favors the pedagogical focus on collaboratively negotiating meanings, at the same time that it makes room for critical work on language and the processes of meaning-making in online environments.
\end{abstract}

Keywords: collaborative interaction; language education; digital technology, teacher mediation.

\title{
RÉSUMÉ
}

Cet article a pour but de présenter et de discuter des usages et des pratiques de langage qui ont favorisé la participation et l'interaction collaborative entre des étudiants de premier cycle universitaire sur une plateforme utilisée pour l'enseignement en ligne. Les pratiques d'apprentissage se sont déroulées dans le cadre d'un cours de morphosyntaxe du français de la licence en Lettres - Français de l'Université de Brasília pendant la période 
d'enseignement distanciel découlant du scénario de pandémie en 2020. Soutenues par les notions de médiation par le texte et d'apprentissagel interaction collaborative (WARSCHAUER, 1997; ZOUROU, 2007; $B R A G A, 2013)$, les pratiques visaient à offrir un apprentissage de la langue et sur la langue française qui prend pour ressource textuelle de réflexion le propre matériau linguistique-discursif construit par les étudiants lors de leurs interactions dans l'environnement en ligne. Les récits des étudiants indiquent que la perspective de l'éducation en ligne adoptée favorise la focalisation pédagogique sur la négociation collaborative des sens, tout en ouvrant espace à un travail critique sur le langage et les processus d'élaboration de significations dans les environnements en ligne.

Mots-clés: interaction collaborative; éducation en langues; technologie numérique; médiation enseignante.

\section{Introdução}

A pandemia apressou o passo das tecnologias digitais na educação e mudou completamente a forma como ensinamos. O isolamento social imposto pelo vírus da Covid-19 desde o primeiro semestre letivo de 2020 nos tirou da sala de aula física, espaço onde estávamos habituados a existir e a nos formar cotidianamente como professores e estudantes, não nos deixando outra alternativa senão ir para os espaços virtuais de aprendizagem. Assim, o que antes era uma opção para muitos tornou-se, quase que da noite para o dia, uma necessidade para todos. A integração de recursos digitais e seus letramentos às práticas de ensino, preconizada como urgente há pelo menos duas décadas pela pesquisa nas áreas da educação e dos estudos da linguagem com foco em tecnologias, assumiu um caráter emergencial impondo-se definitivamente nas aulas da educação básica ao ensino superior.

Nesse novo cenário, que se tem chamado de ensino remoto emergencial, todos os professores, com ou sem formação prévia para assumir esse formato de docência, com maior ou menor sintonia com a cultura digital, e até mesmo aqueles que já integravam as tecnologias digitais e os espaços online às suas práticas de ensino foram desafiados pelas drásticas mudanças metodológicas que tiveram que trazer a seus cursos e disciplinas, até então desenhados para o espaço presencial. Afinal, uma coisa é integrar ao ensino presencial uma parte de práticas 
online viabilizadas por recursos digitais, e outra coisa, bem diferente, é ver-se diante da necessidade de fazer acontecer a integralidade das atividades de aprendizagem em um ambiente digital que oferece outras dinâmicas de compartilhamento e de construção do conhecimento, de comunicação e interação entre os sujeitos participantes do processo de aprendizagem, distintas daquelas que ocorrem no espaço físico da aula.

A fim de adaptar-nos ao modelo temporário de educação, organizaram-se debates e rápidas formações internas nas instituições de ensino públicas e privadas pelo país afora, com o objetivo de traçar orientações e procedimentos pedagógicos que pudessem ser transpostos do presencial para o remoto digital. Na universidade em que atuo, os debates foram pautados tanto pela potencialidade dos recursos dos ambientes virtuais de aprendizagem e plataformas online que tínhamos a nossa disposição, como, e sobretudo, pela garantia do acesso dos estudantes a esses espaços da internet. A inclusão, e não o contrário, foi o consenso entre os docentes para organizar o funcionamento de nossas disciplinas de graduação e de pós-graduação no remoto emergencial.

No entanto, para além das orientações e entendimentos coletivos, a escolha entre este ou aquele ambiente ou plataforma, entre orientar o foco para o conteúdo ou para as relações dialógicas entre os estudantes, entre priorizar aulas e atividades síncronas ou assíncronas sempre decorre das soluções pedagógicas encontradas por cada professora e professor para promover práticas de aprendizagem coerentes com os objetivos e programa de seus cursos. Por trás de cada uma dessas decisões está em jogo uma questão da maior relevância para a educação em línguas adicionais ${ }^{2}$, pelo potencial de (co-)construção de sentidos e de competências linguísticas que pode trazer à aprendizagem mediada por tecnologias digitais: a interação pela linguagem, e os diferentes tipos de interação que se pode promover nesses ambientes entre os atores envolvidos no processo de ensino e aprendizagem.

2. Emprego o termo línguas adicionais para referir-me ao francês e a outras línguas não maternas por considerá-las como línguas que se aprende por acréscimo e que vêm somar-se ao repertório linguístico do estudante. Além disso, o termo nos permite uma aproximação metodológica com o contexto do aluno e as práticas sociais de sua comunidade (LEFFA; IRALA, 2014). 
O objetivo deste $\operatorname{artigo}^{3}$ é discutir como esse potencial da interação foi explorado na plataforma Teams em uma disciplina de graduação do Curso de Letras Francês ofertada no ano de 2020, durante o período de ensino remoto emergencial, na universidade em que atuo. Para abordar a questão da interação online, procuro olhar para a linguagem empregada na proposição e na mediação das práticas de aprendizagem, avaliando se os usos dessa linguagem desempenharam, como desejado, algum papel relevante para a adesão e o engajamento colaborativo dos estudantes (às)nas interações e debates.

Tendo esse objetivo em vista, apresento inicialmente os pressupostos teóricos que embasam as noções de mediação pelo texto e de interação colaborativa que serviram de base à concepção e à realização das práticas de ensino e aprendizagem em uma turma online da disciplina de morfossintaxe do francês. São destacadas, no texto, algumas das vantagens da integração de tecnologias digitais para a prática da interação pela linguagem entre pares em ambientes de aprendizagem online, relacionando os usos desses recursos aos princípios da metodologia da educação online. Na sequência, apresento e discuto duas atividades desenvolvidas na plataforma Teams para o ensino de morfossintaxe do francês, buscando trazer exemplos de como a reflexão sobre os usos da língua francesa foi expandida para além da estrutura, a fim de envolver os estudantes em interações dialógicas que levassem a discutir os efeitos de sentido criados nos textos em função das escolhas linguísticas feitas pelos seus autores.

\section{Interação colaborativa e educação online em línguas}

A possibilidade de se incrementar a interação e a construção colaborativa de conhecimento entre estudantes é uma das mais potentes vantagens relacionadas ao uso das tecnologias digitais para a educação em línguas, sobretudo quando se conta com recursos interativos da web 2.0 que trazem novas dinâmicas ao aprender e produzir conjuntamente. Um dos primeiros a investigar o tema foi Mark Warschauer, que, em

3. Agradeço a Maya, Sofi, Débora, Muriel, Flora, Alice Braga, Bell e Joshua, assim como aos monitores Ravi e Fernando (nomes fictícios), pelas contribuições e apoio à realização deste estudo. 
um artigo ${ }^{4}$ de 1997 considerado referência na área (ZOUROU, 2007), defendia o potencial da interação mediada por computador para a colaboração entre pares na aprendizagem de uma língua estrangeira. No texto, o autor lembra inicialmente que a linguagem possui duas funções principais, tanto na sociedade quanto na aula de língua: permite-nos "interagir comunicativamente, e construir experiência", isto é, "interpretar experiências por meio da construção de sentidos" (WARSCHAUER, 1997, p. 472), e considera que a a comunicação via internet faz com que as duas funções possam ocorrer ao mesmo tempo, rompendo barreiras entre o que seria considerado historicamente do território do discurso (interação) e do território dos textos escritos (interpretação e reflexão).

Partindo desse pressuposto, e tendo em mente um ensino de línguas ancorado na perspectiva sociocultural e também nos estudos de Bakhtin/Voloshinov (Marxismo e filosofia da linguagem, [1977] 2009) sobre o papel da interação para moldar a experiência discursiva dos sujeitos, o pesquisador defende que a construção de sentidos de forma colaborativa se dá via "mediação pelo texto" (text mediation), ou seja, tomando textos como "dispositivos de reflexão" (thinking devices) a fim de gerar novos sentidos de forma colaborativa (WARSCHAUER, 1997, p. 471). À medida que interagem com os textos de apoio às tarefas mediadas, os estudantes não só vão criando novas interpretações de sentido, como também usam a própria linguagem empregada nas conversas colaborativas com seus colegas como ferramenta para o desenvolvimento da linguagem e a aprendizagem na língua-alvo (WELLS e CHANG-WELLS, 1992, citados por WARSCHAUER, 1997, p. 471). Para Warschauer, a aprendizagem mediada via computador é propícia à dinâmica da interação-reflexão entre pares devido às características peculiares de registro dos textos, aos quais se pode sempre voltar para reavaliar, editar ou reescrever, e de tomada de turno do ambiente, que favorece mais equilíbrio e igualdade de participação entre estudantes que no presencial. De acordo com o autor, esse tipo de mediação pelo texto permite conectar a conversa e a colaboração na sala de aula a práticas de interação, expressão, letramento e pensamento crítico. $\mathrm{Na}$ análise de Zourou (2007), a noção de colaboração apresentada por

4. Trata-se de Computer-mediated collaborative learning : theory and practice, publicado no Modern Language Journal em 1997. As traduções de excertos do texto aqui apresentadas são de minha responsabilidade. 
Warschauer refere-se menos à ideia de realização coletiva de uma tarefa em todas as suas etapas, tal como é compreendida pelas ciências cognitivas, que a uma forma de colaboração ancorada na negociação de sentidos, visão que se filia aos estudos da linguagem, em especial à aprendizagem de línguas. Para a autora, essa "escorregadela semântica" (ZOUROU, 2007, online) não impede, no entanto, que haja interlocução entre as duas perspectivas com respeito a seu objetivo comum, o de compreender os processos de construção colaborativa de sentidos nas aprendizagens mediadas por computador.

É importante ressaltar, neste momento, o quanto a perspectiva da interação mediada proposta por Warschauer à virada do século encontra eco em estudos mais recentes sobre letramento digital e crítico, em especial naqueles que incluem as noções de agência e de (re)design de textos como forma mais emancipadora, para os estudantes, de representar o mundo a partir de sua própria linguagem, subjetividade e marcas identitárias. Uma das pesquisadoras cuja perspectiva de aprendizagem mediada dialoga com a visão de Warschauer é Braga, que defende que recursos digitais, e em particular os da web 2.0, incentivam "propostas de ensino menos centradas no professor e mais voltadas para a interação e o diálogo, já muito defendidas pelas propostas pedagógicas de orientação sócio-interacionista" (BRAGA, 2007, p. 184), e que, quando usados, trazem à prática pedagógica "formas mais dinâmicas de implementar modos colaborativos ou reflexivos de ensinar e aprender" (BRAGA, 2013, p. 58-59). Um exemplo de projeto educacional inspirado nos ambientes da web 2.0 são os ambientes virtuais de aprendizagem (AVA), plataformas que permitem reproduzir muito das práticas da aula presencial nos espaços online, uma vez que seus recursos carregam as principais características dessa geração da web: a possibilidade de publicar conteúdo autogerado, multimodal e interativo, de interagir com outras pessoas e colaborar em comunidades online.

Em uma análise fina dos AVA e suas potencialidades para apoiar metodologias de ensino que buscam promover maior autonomia e agência dos alunos sobre seus próprios processos de aprendizagem, Braga comenta algumas vantagens, mas também os limites, desses ambientes com relação à interação e à construção colaborativa da aprendizagem. Em relação aos pontos mais positivos dessas plataformas, a possibilidade de se obter "uma participação mais ampla" dos 
estudantes com relação à sala de aula presencial (BRAGA, 2013, p. 82), devido à própria ampliação do espaço-tempo no digital, talvez seja o destaque da autora que encontre maior interlocução com a dinâmica da interação-reflexão proposta por Warschauer, como vimos acima. Isso acontece sobretudo nos fóruns por escrito, uma vez que a dinâmica do assíncrono permite a cada estudante aderir às interações em seu ritmo pessoal, tomando o tempo de ler o que está em debate e amadurecer ideias antes de registrar a sua participação no fluxo da conversa. Além dos fóruns, outros espaços de interação assíncrona, tal como o bate-papo [hoje muito usado dentro das chamadas de vídeo], o fácil compartilhamento de material de apoio ao curso, de textos e links para outros espaços da internet fazem dessas plataformas espaços favoráveis às aprendizagens colaborativas, destaca Braga. De fato, esses são recursos valiosos para o ensino de uma língua estrangeira/ adicional pelas oportunidades de troca e colaboração entre estudantes que viabilizam, tanto quanto pela elasticidade que conferem ao tempo destes para voltar aos seus textos e refletir sobre modos linguísticos de construção de sentidos na língua de aprendizagem. No entanto, é preciso ressaltar que a obtenção desses resultados depende fundamentalmente do uso que os professores atribuirão aos recursos disponíveis, ou seja, da mediação docente nesses ambientes, o que nos leva inevitavelmente a discutir os limites dos ambientes digitais para a aprendizagem.

Ambientes virtuais de aprendizagem nem sempre são convidativos aos olhos dos estudantes: nas aulas, ouve-se comentários críticos sobre a estrutura dessas plataformas, que ao tentar reproduzir o espaço presencial da aula acabam por entregar uma moldura rígida, com interfaces de navegação pouco atraentes (sobretudo aos olhos dos usuários costumeiros de redes sociais) ou pouco intuitivas, o que compromete a exploração plena dos recursos da plataforma pelos estudantes. Tal dificuldade foi também observada em uma experiência de ensino pela plataforma Moodle conduzida por Rozenfeld et al. em 2010 (citadas por RIBAS e TAGATA, 2015, p. 362), em que se observou que os alunos "tiveram dificuldades em compreender a organização das unidades temáticas do fórum, ignorando suas funcionalidades, formas de organização e de funcionamento."

Mas, para além dessas questões mais técnicas, é comum ainda, mesmo nas aulas da graduação, observar que alguns estudantes têm 
dificuldade em engajar-se nas práticas de interação pela linguagem com seus colegas. Para Braga (2013, p. 83), isso se deve a uma "cultura de aprender ainda [...] fortemente centrada na figura do professor", em que os estudantes respondem ao professor sem necessariamente interagir com as colocações e comentários dos seus colegas em um debate. Semelhante análise da "cultura de aprender dos alunos" é trazida por Ribas e Tagata (2015, p. 363), segundo os quais, mesmo nas interações com os colegas, os estudantes ficariam ansiosos pela validação de suas respostas por parte do professor. Ainda, há os não-ditos, como bem lembra Braga (2013), dificuldades dos estudantes com relação à aprendizagem que, quando não são expressas verbalmente, tampouco se deixam perceber nos ambientes de interação online, onde não temos acesso à linguagem corporal que geralmente mapeia o que ocorre na sala de aula presencial. Esse parece-me ser, talvez, o ponto mais sensível da educação no remoto pandêmico, por envolver questões pessoais, socioeconômicas ou de organização familiar (uma vez que todos trabalhamos e estudamos em casa) que nem sempre os estudantes estão dispostos a verbalizar ou discutir com seus professores.

Todas essas questões podem estar na origem da baixa adesão e engajamento de alguns estudantes (às)nas práticas de aprendizagem online, e por essa razão "é preciso desenvolver nos alunos as habilidades necessárias para esse tipo de discussão coletiva” (BRAGA, 2013, p. 83). É preciso conversar, mostrar-se aberto a oferecer ajuda aos estudantes: para isso servem todos os canais de comunicação das plataformas de ensino online. Somado a um diálogo aberto que busca a inclusão, é necessário, sobretudo, construir formas de ensinar e aprender menos centralizadoras, assim como são os espaços da web 2.0 que inspiraram a criação desses AVAs.

Descentralizar as ações de ensino e aprendizagem, tendo em vista uma participação mais autônoma, emancipada, crítica e reflexiva dos estudantes nas práticas de aprendizagem depende essencialmente da mediação do professor e de suas escolhas pedagógicas. E essa mediação começa com o desenho do curso, na escolha do ambiente online em que se realizará a aula remota, na definição de um formato de atividades que vá privilegiar a interação entre colegas em detrimento dos "exercícios de língua”, que favoreça a discussão de ideias, a reflexão crítica, a 
observação dos usos da linguagem no grupo de colegas como matéria para o desenvolvimento de habilidades de linguagem na língua alvo.

Em tempos pandêmicos, a organização dos docentes para a retomada das aulas trouxe à tona uma questão da maior importância: que abordagem de ensino situado no remoto iríamos adotar. Logo compreendeu-se que não se tratava de seguir os princípios da EAD (Educação a Distância), mas sim de operar uma transposição temporária daquilo que fazíamos no espaço físico da aula para os ambientes online. Embora a Educação a Distância se paute por princípios de interatividade e aprendizagem colaborativa e cooperativa, trata-se de uma modalidade de ensino que visa um alto grau de autonomia, e por essa razão se organiza em torno à disponibilização de grande quantidade de conteúdos, a fim de que os participantes possam definir os passos de sua própria aprendizagem (MOREIRA; SCHLEMMER, 2020), com a mínima interação entre as pessoas. Assim, é considerada uma modalidade de ensino massificada (SANTOS; CARVALHO; PIMENTEL, 2016), em que há grande interatividade, mas pouca interação situada entre os estudantes. Por esse motivo, suas práticas não correspondem a abordagens de ensino e de aprendizagem de línguas com foco na interação colaborativa entre estudantes.

Em oposição a esse formato de ensino, a educação online aparece-nos como a modalidade de ensino que mais dialoga com os posicionamentos teórico-metodológicos discutidos acima, pois prevê práticas que promovem a autoria dos estudantes, a aprendizagem crítica, colaborativa, cujo foco "não está nem no conteúdo, nem no sujeito, mas na relação dialógica que se estabelece entre todos os atores humanos (estudantes, professor, tutor) mediada pelas TD e viabilizadas tanto por meio da comunicação síncrona, quanto assíncrona" (MOREIRA; SCHLEMMER, 2020, p.17). Ao mesmo tempo, trata-se de uma abordagem que permite agregar ao ensino de línguas alguns dos elementos da cibercultura, tais como a criatividade, a autonomia, os letramentos digitais e críticos, como defendido por Santos, Carvalho e Pimentel:

Contrapondo as práticas massivas de ensino na $\mathrm{EAD}$, que tem se tornado o modelo hegemônico, adotamos a abordagem da "educação online" (SANTOS, 2005; SANTOS; SILVA, 2009), que é concebida para promover a (co)autoria do aprendente, a mobilização da aprendizagem crítica e colaborativa, a mediação docente voltada para interatividade e partilha, traz a 
cibercultura como inspiração e potencializadora das práticas pedagógicas, visa a autonomia e a criatividade na aprendizagem. Em nossa concepção de educação online, o papel do docente é fundamental no processo formativo dos estudantes, sendo necessária uma mediação ativa para a promoção da aprendizagem colaborativa, que pressupõe a interatividade. (SANTOS; CARVALHO; PIMENTEL, 2016, p. 24)

Não se discute o papel decisivo do professor como mediador privilegiado e mais experiente no processo de educação em línguas. Mas como assegurar uma mediação no ensino remoto emergencial que seja de fato convidativa à troca, à interação, à reflexão e à construção de sentidos em colaboração com os colegas? Em outras palavras, como fazer uma aprendizagem crítico-reflexiva baseada na interação acontecer no online em um momento social e de saúde pública tão sensível para todos os atores envolvidos naquele processo de aprendizagem? Uma resposta efetiva que tenho encontrado, até aqui, é a da mediação pela linguagem. Em uma disciplina de graduação cujo foco é o estudo sobre a língua, pareceu-me oportuno aproveitar os espaços de escrita online para explorar ainda mais os usos e as estratégias de linguagem de minha própria mediação docente, como meio de envolver os estudantes na interação/reflexão proposta no ambiente online em que trabalhamos durante o primeiro semestre letivo pandêmico de 2020. É sobre isso que discutirei a seguir.

\section{Interação e colaboração na morfossintaxe do francês}

Que lugar a interação pela linguagem pode e deve ocupar na educação online em uma disciplina de morfossintaxe do francês? Mais do que buscar respostas imediatas e esclarecedoras sobre como se daria a transposição do ensino presencial para o remoto emergencial, a pergunta me ofereceu o norte para (re)organizar minha prática docente nos tempos da pandemia.

Após um período inicial de suspensão de suas atividades administrativas e acadêmicas para planejamento interno, e em consonância com as determinações governamentais de isolamento social durante a pandemia do Covid-19, a universidade em que atuo retomou as atividades de ensino do semestre letivo $1^{\circ} / 2020$ em agosto desse mesmo 
ano, com orientações claras sobre as atividades síncronas e assíncronas que poderiam ser desenvolvidas no contexto de ensino não presencial. Como apoio a essa modalidade de ensino, nos foi sugerido um leque de atividades e de recursos digitais, e a opção de realizarmos as aulas em uma das plataformas institucionais oferecidas pela universidade à sua comunidade de discentes, docentes e técnicos: Aprender 3 (Moodle) ou Teams (Microsoft), espaços que nos facilitariam manter o registro do ensino no período que pudesse também ser facilmente acessado pelos estudantes. Editais de inclusão digital organizados pela universidade contemplaram algo perto de 3 mil discentes com computadores e conexão à rede, com o objetivo de garantir aos estudantes em situação de vulnerabilidade socioeconômica as condições mínimas (ao menos, as técnicas) necessárias ao acompanhamento das atividades acadêmicas remotas.

O momento era de grande mudança para todos nós. Era preciso, sobretudo, pensar mais além da questão técnica: a inclusão digital maior viria de uma postura pedagógica de inclusão e acolhimento metodológico, pois muitos de nossos estudantes, embora hábeis usuários da internet, não estavam habituados a frequentar cursos em modalidade totalmente remota - assim como esse novo ambiente de ensino tampouco era familiar a muitos docentes. No início desse retorno às aulas, marcado por muitas incertezas com relação às possibilidades reais dos discentes trabalharem no modo remoto, a orientação pedagógica da universidade foi a de apostarmos mais em atividades assíncronas, pois demandam menor tráfego de dados para a sua realização, que em atividades síncronas por meio de videochamadas e, assim, facilitarmos a participação discente nas práticas de aprendizagem.

Diante desse cenário, a plataforma Teams me pareceu a mais adequada para realizar o tipo de educação online que pretendia construir com a minha turma de Morfossintaxe do Francês, ofertada aos Cursos de Letras naquele semestre. Embora a disciplina de morphosyntaxe seja especialmente voltada para o estudo da gramática do francês, costumo trazer a ela uma abordagem socionteracionista da língua e o objetivo geral de refletir sobre as estruturas de composição de frases e textos, e os efeitos de sentido que nossas escolhas linguísticas têm sobre os discursos. Além dos recursos de comunicação, videochamada e compartilhamento de arquivos terem funcionamento semelhante ao de outros 
espaços e redes da web 2.0 - o que, supõe-se, ofereceria intuitividade de navegação, a disposição da timeline ocupando o grande espaço central da plataforma foi elemento decisivo para a escolha do ambiente, pois, na minha percepção docente, esse seria o espaço privilegiado para as interações entre os participantes daquela turma.

A partir dessa escolha, organizei uma metodologia de ensino e aprendizagem baseada na mediação pelo texto, cujas leituras e interpretações se construiriam nas interações colaborativas entre os estudantes no espaço de conversa. Assim, a disciplina que no presencial tem dois encontros de $1 \mathrm{~h} 50$ por semana, no espaço online dividiu-se entre um encontro síncrono semanal por videochamada e uma atividade assíncrona, geralmente quinzenal, para dar tempo aos estudantes de se envolverem na sua realização e no aprofundamento do debate. Ao longo do semestre, 17 estudantes participaram ativamente das atividades na equipe da plataforma (intitulada MSF 2020-1), além de mim, a professora responsável pela oferta da disciplina (daqui por diante, C.), e os monitores Ravi e Fernando. Dentre esses, oito discentes consentiram em participar deste estudo ${ }^{5}$, sendo deles, portanto, os excertos de textos que compõem o material empírico analisado nesta seção.

A participação dos monitores Ravi e Fernando, estudantes dos cursos de graduação em Letras Francês e de Línguas Estrangeiras Aplicadas ao Multilinguismo e ao Ciberespaço (LEA-MSI) foi fundamental para o desenvolvimento da disciplina, e decisivo para o engajamento dos estudantes nas práticas de aprendizagem propostas. A presença constante dos monitores nas aulas síncronas e nas atividades assíncronas contribuiu para tornar as relações no espaço da aula mais horizontais, pelos laços afetivos e identitários que se criam entre os discentes, muitas vezes colegas de turma em outras disciplinas do currículo. Um ponto positivo destacado pelos estudantes da turma foi a forma de comunicação e de ajuda mútua que conseguimos estabelecer na plataforma, como vemos a seguir nas narrativas discentes de avaliação do curso.

A comunicação com a professora e os monitores foi muito legal! A comunicação foi bem clara durante todo o semestre, e C. e Ravi estavam o tempo

5. Todos os estudantes, bem como os monitores da turma, são identificados no texto mediante pseudônimos por elas/eles mesmos indicados em Termo de Consentimento Livre e Esclarecido, a fim de resguardarmos as suas reais identidades. 
todo disponíveis para nos ajudar, acho isso essencial para o funcionamento da disciplina a distância. (Narrativa de Alice $\mathrm{Braga}^{6}$, dezembro de 2020)

Só posso agradecer, além da professora por sua paciência e dedicação, ao Ravi que estava presente em todas as aulas e foi um monitor incrível. Sempre interagi com a classe e dissipei minhas dúvidas. Como estudo espanhol com Ravi, e por isso tínhamos um grupo no WhatsApp, era o suporte por onde achava mais fácil contatá-lo. Ainda que eu não conheça o Fernando, agradeço igualmente a ele por ter sido monitor e ajudar a nossa aula. (Narrativa de Débora $^{7}$, dezembro de 2020).

No espaço de conversa online, a permanência do texto escrito dos estudantes e a dimensão ampliada do tempo (tempo de ler, de refletir, de interagir no assíncrono) deram maior vigor à metodologia baseada na mediação pelo texto já adotada nas aulas presenciais de morfossintaxe do francês. Nossa dinâmica, no online, iniciava-se com a leitura de um texto da esfera pública - em geral, de gêneros jornalísticos tirados de jornais ou de blogs em versão digital, passando pela compreensão global do texto, depois a uma leitura e análise mais detalhada do funcionamento da língua no nível da frase, para enfim voltarmos ao texto/enunciado e construir conjuntamente os sentidos que emergiam daquele texto.

A intenção pedagógica residia na ideia de abordar o estudo da língua francesa apoiando-nos na perspectiva bakhtiniana que vê os textos ou enunciados ("unidade da comunicação discursiva"), e não a oração ("unidade da língua"), o meio pelo qual os locutores se relacionam com o "contexto extraverbal da realidade", a situação, o ambiente social e histórico (BAKHTIN, ([1979] 2010, p. 276-277). Assim, na mediação

6. Tradução livre do original em francês: "La communication avec la professeure et les moniteurs étaient super ! La communication était bien claire pendant le semestre entière et C. et Ravi étaient toujours disponible pour nous aider, je trouve ça essentiel par le fonctionnement de la discipline à distance." (Narrativa de Alice Braga, dez. 2020)

7. Do original em francês: "Je ne peux que remercier, en plus de la professeure pour sa patience et son dévouement, Ravi qui était présent dans toutes les classes et était un moniteur incroyable. J'ai toujours interagi avec la classe et dissipé tous mes doutes. Comme je fais l'espagnol avec Ravi et, par conséquent, nous avions un groupe sur WhatsApp, c'était le support dans lequel j'ai trouvé plus facile de le contacter. Bien que je ne connaisse pas Fernando, je le remercie également d'avoir été un moniteur et d'aider notre classe." (Narrativa de Débora, dez. 2020) 
docente adotada, pretendia que a aprendizagem fosse além do conteúdo, e da estrutura, explorando a relação entre as escolhas linguísticas e os efeitos de sentido criados, para perceber as subjetividades em jogo embutidas nos discursos, tanto os dos outros - que nos chegam massivamente por meio da conexão digital às mídias online, quanto aqueles produzidos pelos próprios estudantes.

Uma das práticas que mais adesões teve no espaço online de conversa foi a que propunha discutir o conceito de postura nos textos: como um falante articula linguística e discursivamente o seu posicionamento com relação ao que diz, e a quem o diz, isto é, a quem endereça o seu enunciado (BARTON; LEE, 2015, 49.) Inserida no tema dos articuladores do discurso (les rapports circonstanciels), a atividade foi desenvolvida na metade do semestre letivo, quando os estudantes já estavam mais habituados com a dinâmica das interações no espaço de conversa da plataforma. Entre os dias $21 / 10$ e $05 / 11$, a atividade gerou 26 comentários de 10 estudantes, além dos da professora e dos monitores, como vemos na figura 1 , adiante.

A atividade proposta convidava os estudantes a articular a leitura do texto teórico sobre o conceito de postura, de Barton e Lee (2015), a dois artigos do gênero jornalístico veiculados em canais diferentes: o primeiro, discutido em atividade assíncrona anterior a essa, Alimentation et climat: l'urgence des choix de nouveau pointée par le GIEC publicado em 08 de agosto de 2019 no canal online da radio francesa RFI - Radio France International; e o segundo, indicado nesta atividade, o texto L'humanité se dirige-t-elle vers le précipice ?' ${ }^{\text {, publicado em }}$ 23 de agosto de 2019 por Traoré Yohane em seu blog pessoal, eleito o blogueiro daquele mês pelo site $<$ mondoblog.org $>$.

8. Alimentação e clima: a urgência das escolhas novamente apontada pelo GIEC. Disponível em: <https://www.rfi.fr/fr/science/20190808-alimentation-climat-urgence-giecsecurite-alimentaire $>$.

9. A humanidade se dirige para o precipício? Disponível em $<\mathrm{https} / / /$ perseverance. mondoblog.org/2019/08/23/lhumanite-se-dirige-t-elle-vers-le-precipice>. 
Figura 1 - Prática textual sobre postura

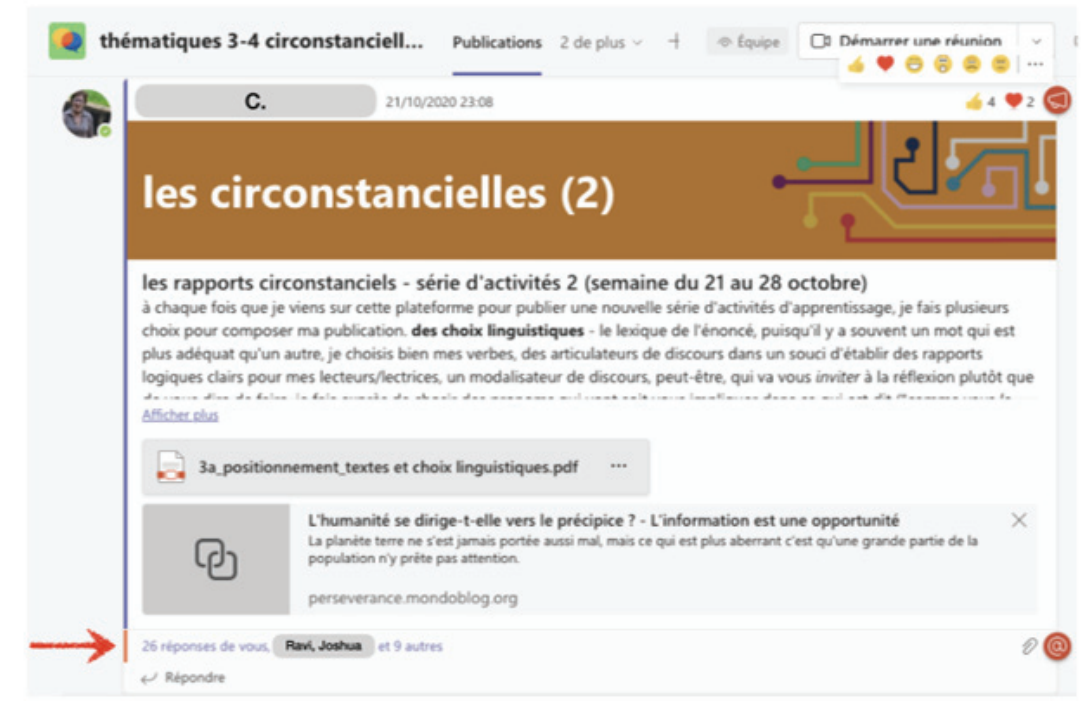

Fonte: arquivo pessoal da autora, do espaço MSF 2020-1 na plataforma Teams

Nosso objetivo era o de promover um debate para identificar os recursos textuais com que cada um dos autores manifesta seu posicionamento com relação à mesma temática do meio-ambiente e do consumismo capitalista. Estávamos assistindo, naquele período da aula, em outubro de 2020, a uma série de incêndios em vastas áreas de mata e de florestas brasileiras e em outros países do mundo, em decorrência das mudanças climáticas e do aumento da temperatura média do planeta. Nossa aprendizagem situada visava trazer a realidade lá de fora para o debate da aula, usando nossa prática mais valiosa - também nosso objeto de estudo e de reflexão: a linguagem. Os gêneros do discurso se modificam conforme os veículos que os transportam são distintos, aprendemos isso há anos, lendo Luis Antônio Marcuschi. A observar apenas os títulos dos artigos, já é possível prever que o texto publicado no blog pessoal dava um tratamento bem distinto ao mesmo conteúdo temático apresentado pelo artigo de jornal da grande imprensa. Mas não foi essa análise que ocupou o centro das atenções na conversa assíncrona entre os estudantes - voltamos a isso posteriormente, em um encontro síncrono por videochamada. 
O espaço da conversa por escrito para essa atividade foi, na verdade, ocupado pelo debate sobre postura. No enunciado da atividade, usei intencionalmente estratégias de linguagem para evidenciar que eu também vinha adotando uma postura discursiva particular na minha mediação docente, desde o início do curso, naquele espaço de escrita online (a cada vez que venho a esta plataforma publicar uma nova série de atividades de aprendizagem, faço várias escolhas para compor a minha publicação. Enunciado de C., em "les circonstancielles (2)", out. 2020; cf. Figura 1, acima). Procurava chamar a atenção dos estudantes, com exemplos, para o modo como eu fazia minhas escolhas de palavras, enquanto professora-mediadora daquele espaço de aprendizagem, buscando sempre um termo mais adequado ao contexto, um conector discursivo que evidenciasse a relação desejada entre ideias, um verbo modalizador que convidasse o estudante à reflexão ao invés de lhe dizer o que ele tinha de fazer. Procurava também destacar minhas estratégias de composição multimodal nos enunciados das atividades propostas, tais como escolha de cor e tamanho da fonte, do tipo de publicação dentre aquelas que a maquete da plataforma web 2.0 oferece (nova conversa ou aviso), da ilustração que compõe o cabeçalho da atividade, de modo que o todo estivesse imageticamente relacionado à temática proposta para debate. Acredito que o enunciado surtiu os efeitos desejados, juntamente com a leitura do texto sobre postura, para desencadear uma interação colaborativa bastante rica entre os estudantes.

[Ravi, 26/10/2020] Hello les gens !! N'oubliez pas cette activité... les textes sont très cools à discuter $\approx$ (6 mentions J'aime)

[Joshua, 26/10/2020] Merci pour l'attention Ravi !!

[Joshua, 26/10/2020] Sur le premier texte, j'ai appris que le débat concernant $<<$ la posture $>>$, ou l'attitude de l'auteur, est complexe et dépend de plusieurs éléments. Des $<<$ postures épistémologiques $>>$ de chaque individuel sont présent dans le discours et la posture d'une personne en regardant quelque thème. Je crois que le texte m'a fait réfléchir un peu plus profondément sur le thème des positions des auteurs, donc merci pour la partage!! ( 7 mentions J'aime)

[Maya, 26/10/2020] Avec la lecture du texte j'ai pu comprendre de quoi s'agit cette « postura » et pourquoi elle est tellement importante quand on analyse un discours n'importe quel. Alors j'ai compris que cette « postura » peut être définie comme un positionnement de l'individu qui parle par rapport au sujet dont il parle. Le locuteur va faire des choix linguistiques qui ne sont pas du 
tout aléatoires, mais qui sont au contraire pensées en prenant en compte à qui on parle et de quelle manière on veut montrer notre opinion. Ça m'a fait réfléchir sur le fait qu'il n'existe pas de discours neutres, même si l'auteur en donne l'impression. Et ce sont les choix linguistiques qui vont permettre cette illusion d'impartialité (j'y crois haha). C'est juste une réflexion... (3 mentions J'aime)

[Débora, 27/10/2020] J'ai compris que cette 〈〈postura») de l'auteur influence dans plusieurs aspects du texte et dans le contexte d'internet encore plus, car en plus du choix des mots et des structures l'auteur dispose encore de plusieurs moyens (changement de couleurs, ajout d'émojis, de vidéos, d'images etc). Cependant, ce qui a le plus retenu mon attention a été la réflexion sur l'espace du lecteur sur le web et les différentes «posturas» et «práticas» qu'il peut avoir, ce qui crée une relation d'échange innovante avec de nombreuses possibilités entre auteur et lecteur qui peuvent changer le sens originel du texte. (think) (2 mentions J'aime)

O lembrete inicial do monitor Ravi para que os colegas da turma participassem do debate deu início a uma série de comentários sobre a noção de postura. Enquanto a participação de Joshua oferece um panorama bem geral sobre a leitura, os 7 likes que ganhou sugerem que ela teve também o papel de chamar os colegas para o debate. $\mathrm{Na}$ sequência, cada colega que entrava na interação trazia mais elementos de interpretação do conceito, e assim foram aos poucos relacionando-o aos seus contextos de interação pela linguagem na sociedade. Maya compartilha sua compreensão da leitura, e arrisca uma reflexão pessoal relacionando o conceito à ideia de que não há discursos neutros, apenas a ilusão de que isso é possível é dada pelas escolhas linguísticas de cada falante. Débora aprofunda o debate desenvolvido pelos colegas, trazendo a nuance da expressão multimodal que entra na composição dos textos digitais, e destaca o impacto que lhe causou, na leitura do texto teórico, a reflexão sobre a expressão da postura nos espaços reservados aos comentários do leitor na web 2.0 como forma de interação entre autor e leitor que pode gerar novos sentidos para o texto original. À semelhança de Maya, que termina seu comentário com um simpático é o que eu acho, haha, Débora deixa um emoji pensativo no final do seu post.

[Sofi, 27/10/2020] Wow, super le choix du texte!! cela m'a vraiment apporté plusieurs réflexions sur la thématique. En effet, la première chose que je voudrais souligner et la partie du texte qui parle du concept de " posture ", 
qui en résumé serait le positionnement que nous assumons par rapport à ce qu'on dit et à qui on dit. Cela suffit pour comprendre que notre discours est constamment façonné et adapté à différentes situations et moyens discursifs (ce qui nous rappelle beaucoup de Bakhtine, quand il parle des genres de discours, de polyphonie et de dialogisme). Un autre point intéressant de ce texte est lorsque les auteurs parlent de la forme avec l'environnement des médias en ligne ainsi que les réseaux sociaux sont riches en positionnement. Nous permettant cette facilité et même la « liberté» de nous exprimer et de donner notre avis sur n'importe quel sujet. Mais ce texte nous amène à réfléchir justement, sur la façon dont comment nous sommes-nous positionnés dans les réseaux et comment nos discours et identités sont façonnés et tissés par d'autres discours. «L'expérience verbale individuelle de l'homme prend forme et évolue sous l'effet d'une interaction continue et permanente avec les déclarations individuelles de l'autre» (BAKHTINE, 2010). (3 mentions J'aime)

[Flora, 28/10/2020] J'ai trouvé très intéressant le concept de «postura» (positionnement) parce que ça nous fait réfléchir à nos choix verbaux ou non verbaux quand on produit un texte verbal ou oral, ce qui pourra évidemment révéler le but de notre énoncé, notre opinion et notre idéologie. Comme Sofi a bien remarqué, Bakhtine situe les énoncés dans des contextes concrets et réels. De cette façon, si c'est impossible de penser à un texte isolé de son contexte, cela nous mène à conclure que les énoncés ne sont jamais neutres et que les choix linguistiques ou non linguistiques vont justement dénoncer l'avis de l'énonciateur. Faire attention aux choix est donc décisif pour définir quel est notre positionnement, parce que si on ne fait pas de bons choix, les interlocuteurs peuvent peut-être ne pas comprendre nos intentions. En ce qui concerne les analyses des textes, je pense alors qu'il nous sera toujours fondamental identifier, analyser et réfléchir sur les choix de l'auteur du texte. (2 mentions J'aime)

Seguindo em interlocução com os colegas que já participavam do debate, Sofi adere à interação relacionando o conceito de postura fornecido por Barton e Lee aos conceitos de polifonia e dialogismo de Bakhtin. Foi uma surpresa bastante agradável para mim ler esse comentário, pois ele mostrava que a interlocução estava se dando também entre esta e outra(s) disciplinas da graduação em que estudavam, naquele momento, a análise e a produção de textos desde a perspectiva dos gêneros do discurso de Bakhtin. Sofi comenta ainda o quanto os nossos discursos e identidades são moldados pelos discursos dos outros, sobretudo nos espaços de interação da web 2.0. Flora, por 
sua vez, destaca a importância do conceito de postura, que nos faz pensar sobre o objetivo, a opinião e a ideologia que nossos enunciados carregam, segundo as escolhas que fazemos para compô-los. Resgata o comentário de Sofi sobre Bakhtin, lembrando a relação entre os contextos concretos e reais em que se produzem os enunciados e a não neutralidade dos textos, para reafirmar, assim como seus colegas, a importância das escolhas linguísticas para expressar as reais intenções comunicativas do falante.

Após o comentário de Flora no fio da conversa, seguiram-se outros de mais colegas, além de Bel e Joshua. Foi interessante notar que minha participação não interrompeu o ciclo de interações entre os estudantes, pelo contrário: acredito que isso se deva à postura escolhida para a mediação, focada em incentivar o aprofundamento do debate e em renovar o convite à conversa buscando relacionar o tema às práticas reais de interação e de uso da linguagem dos estudantes nos espaços da web 2.0.

Ainda na temática dos articuladores de discurso, uma segunda atividade que promoveu uma grande interação entre os estudantes foi uma atividade de reescrita de texto em que se buscava trabalhar diferentes possibilidades de expressão da concessão em francês. Do mesmo modo que na atividade anterior, o texto usado pela professora mediadora no enunciado da atividade (cf. Figura 2) jogava com a linguagem, por um lado anunciando já alguns conectores do discurso empregados para expressar a concessão (apesar das aparências, ainda que pareça difícil, a coisa não é tão complicada assim) e, por outro, abrindo o convite com uma linguagem solta e descontraída em francês (na capa dos jornais esta manhã: [...] apesar da derrota, os republicanos da Virgínia Ocidental estimam que... (FranceInfo) e logo penso, legal, uma boa reflexão para a morfossintaxe do francês (emoji piscando). A aposta no convite à prática de linguagem gerou 18 comentários, em uma interação envolvendo 10 colegas, além da professora mediadora, como vemos na Figura 2, abaixo. 
Figura 2 - prática textual sobre a concessão

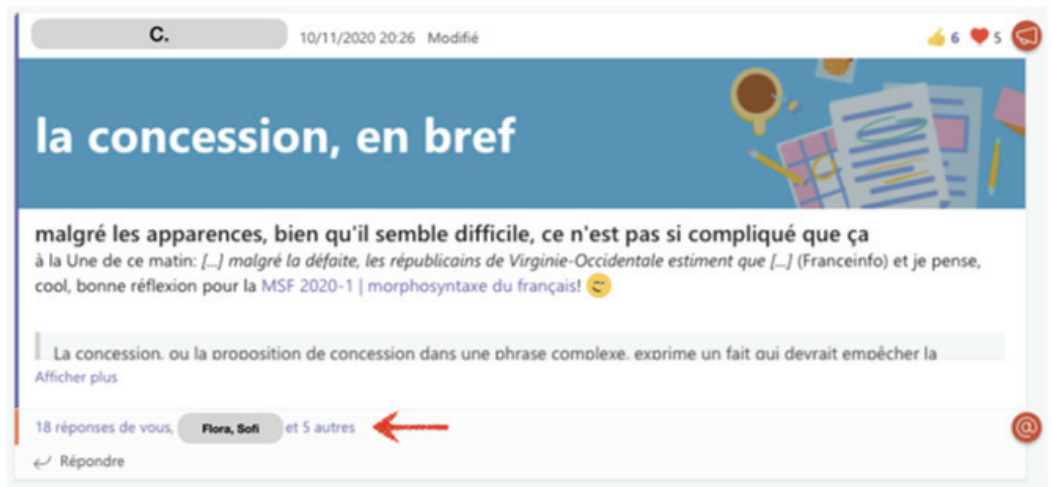

Fonte: arquivo pessoal da autora, do espaço MSF 2020-1 na plataforma Teams

O primeiro comentário no fio da conversa, postado por Flora, logo anuncia que dos articuladores de discurso, as expressões de concessão são as suas preferidas, além de serem "as mais bonitas". A expressão do riso descontraído juntamente com o emoji simpático sugerem sua adesão ao convite e à proposta de atividade, que ela comenta positivamente. Tratava-se de um exercício de reformulação textual a partir do título de jornal: Élection américaine: malgré la défaite, les républicains de Virginie-Occidentale estiment que Trump "ne doit pas se laisser faire" 10 , em que os estudantes deveriam explorar outros meios de construir uma relação de concessão entre as orações, preservando o sentido inicial do texto.

[Flora, 11/11/2020] Ah, d'abord je dois dire que j'adore les expressions de concession (je ne sais pas pourquoi, mais c'est le rapport logique que je trouve le plus intéressant et beau hehehehe 7 ). Bon, j'ai bien aimé cette proposition d'activité, professeure C., et pour ce titre, moi je proposerais ces deux autres écritures: Élection américaine: En dépit de la défaite, les républicains de Virginie-Occidentale estiment que Trump «ne doit pas se laisser faire»; et aussi Élection américaine: Bien que Trump ait perdu les élections présidentielles, les républicains de Virginie-Occidentale estiment qu'il «ne doit pas se laisser faire». Et vous, mes camarades? Vous avez pensé à quelles autres écritures?

10. Eleições americanas: apesar da derrota, os republicanos da Virgínia Ocidental estimam que Trump não deve se deixar vencer. France Info de 10 nov. 2020. 
[C. 11/11/2020] La coïncidence, moi aussi, Flora hehe.... c'est pourquoi je commence par la concession.

[C. 11/11/2020] Tes propositions de réécriture sont bien justes, aussi bien du point de vue syntaxique que de celui du sens, Flora (-)

[C. 11/11/2020] On pourra toujours jouer sur le sens de ce titre aussi, hein, classe de MSF 2020-1 | morphosyntaxe du français... par exemple, en faisant de petites modifications (lexique) au texte, tout en gardant l'idée centrale de la défaite.

[Flora, 11/11/2020 10:27] Personnellement je préfère la proposition “Élection américaine: Bien que Trump ait perdu les élections présidentielles, les républicains de Virginie-Occidentale estiment qu'il 'ne doit pas se laisser faire", parce que là je sens que le fait d'avoir perdu les élections est mis en relief et est plus évident alors... $(\approx)$. Mais je ne sais pas si vous avez cette même sensation. (4 mentions J'aime)

[Débora, 11/11/2020] Salut, salut! je suis d'accord avec Flora, cette activité est vraiment cool (haha). Eh bien, je l'ai fait comme ça: «Élection américaine: Trump a beau perdu, les républicains de Virginie-Occidentale estiment que Trump «ne doit pas se laisser faire». Pour moi, l'utilisation de la préposition « a beau» dans cette phrase, apporte une idée que les républicains ne savent pas perdre. Car même si Trump a perdu les élections, ils ne sont toujours pas résignés. (drôle) $\cong(4$ mentions J'aime)

É interessante notar o quanto esse tipo de atividade de reformulação textual engaja os estudantes no debate de forma descontraída e com real motivação para explorar os possíveis usos da língua que estudam e testar os sentidos provocados por suas escolhas. Tanto é assim que a própria Flora, que havia sido a primeira a postar uma proposta de texto, volta ao debate com outra proposta de construção textual, com o conector de discurso bien que para dar destaque, como ela diz, ao fato de Trump ter perdido as eleições. Débora, por sua vez, propõe a expressão avoir beau, que na sua opinião, dá maior ênfase ao fato de os perdedores não terem aceito a derrota. Volto, adiante no fio da conversa, a essa proposta de Débora para trazer uma sugestão de ajustamento linguístico, lembrando que a sintaxe da expressão pede o verbo no infinitivo ("mais attention à la syntaxe: avoir beau + verbe à l'infinitif...”), mas também procurando mostrar, pela marca fonética da maior parte dos verbos em francês, que ela tinha razão em se confundir. 
[Alice Braga, 13/11/2020] Saluuut! J'ai trouvé cette activité très amusante! Et j'ai ri beaucoup de ce que tu as dit Sofi, c'est vrai que cette préposition donne une idée que les républicains n'accepte jamais sa défaite hahahahah (3.) Mois, j'écrirai comme ça: Élections américaines: Trump refuse sa défaite, si bien que les républicains de Virginie-Occidentale estiment qu'il «ne doit pas se laisser faire». (2 mentions J'aime)

[Bel, 14/11/2020] Coucou, excuse-moi pour mon retard, c'est juste ça Flora, je suis vraiment d'accord avec tu, j'ai trouvé cette activité essentielle pour notre apprentissage. J'avoue que j'ai des difficultés avec la concession, mais alors, J'accepte le défi. Moi, j'écrirai comme ça: Élection américaine: Trump a perdu les élections, pourtant les républicains de Virginie-Occidentale estiment que Trump «ne doit pas se laisser faire». J'ai trouvé difficile de choisir la concession appropriée pour le titre. (3 mentions J'aime)

[Joshua, 15/11/2020] Bonjour mes amis, vous êtes tout bien ?? J'espère que oui ! Regardent les rapports de concession, ils sont très utiles, à mon avis, pour construire un bon texte ; ils peuvent créer un sens de complexité dans la phrase que j'aime beaucoup. La première expression que j'ai pensé, pour changer la phrase de l'exemple de C., c'est le $<<$ en dépit de $>>$, jusque comme Flora a proposé au début. J'ai adoré le commentaire de Sofi et pour ça je te remercie ma collègue, parce que je suis encore un petit peu confus sur l'expression $<<$ avoir beau $>>$, donc son commentaire m'a aidé pour comprendre l'expression. Les autres collègues ont contribué aussi avec différentes expressions de concession, comme $<<$ bien que $>>,<<$ même que $>>$, etc. Il est toujours un défie cette chose d'apprendre une nouvelle langue, mais très positif aussi sans aucun doute!! Concernant la phrase, $\mathrm{j}$ 'écrirais de cette manière ici: Election américaine : les républicains de Virginie-Occidentale estiment que Trump «ne doit pas se laisser faire», cependant la défaite. (3 mentions J'aime)

Vemos nesses excertos como a interação vai se construindo como uma conversa de fato entre colegas, em que uns vão nomeando os outros em seus comentários, em um tecido interativo que busca construir conhecimento juntos enquanto turma. Seguiram-se a esses posts mais alguns comentários meus com propostas de ajustamento linguístico para algumas das reformulações compartilhadas. O comentário final de Joshua funciona como um resumo das diferentes propostas de reformulação textual avançadas pelas colegas, em que ele chega a agradecê-las por lhe esclarecerem alguns aspectos do uso dos articuladores da concessão no discurso, trazendo logo após a sua própria reescrita do título de jornal. Essa adesão às práticas e a vonta- 
de manifesta de incluir as ideias anteriores dos colegas revela traços particulares dos diferentes atores envolvidos naquele contexto social de ensino e aprendizagem. Por um lado, podemos compreender que a mediação docente nesse ambiente conseguiu promover a autoria dos estudantes, a co-construção de práticas desde uma perspectiva crítica, e colaborativa pois constantemente baseada na negociação de sentidos entre eles. Por outro, o lado mais importante: pessoas comprometidas que assumem a responsabilidade sobre o seu próprio processo de aprendizagem, e que sabem que a sua participação, com boa dose de partilha e de acolhimento do outro, contribui também (e muito) com a aprendizagem dos colegas.

\section{Considerações finais e perspectivas de mudanças em/após tempos pandêmicos}

Neste artigo, discuti o potencial de um espaço de conversa online para a interação colaborativa e a construção de conhecimento em/sobre a língua francesa em uma disciplina de graduação em Letras durante o período de ensino remoto decorrente da pandemia da Covid-19. A exposição e a análise de duas práticas de aprendizagem realizadas pelos estudantes serviram de exemplos para revelar um pouco do que aconteceu naquela turma de morfossintaxe do francês. Em especial, pretendi revelar como aprendemos e ensinamos na plataforma online, compartilhando usos da tecnologia digital que nos serviram para fazer daquele primeiro semestre letivo de tempos pandêmicos um período de aprendizagem que fosse significativo e marcante para os estudantes, em termos de trabalho na e sobre a língua francesa.

Procurei, ainda, escolher os excertos de conversas entre os estudantes que revelassem de que modo, nessa turma, foi trabalhada a interação colaborativa - termo que prefiro (a aprendizagem colaborativa), tomando assim a liberdade de ter também a minha "escorregadela semântica", como discutido no início deste texto, para referir-me ao trabalho conjunto de construção de conhecimento sobre o funcionamento da língua a partir da negociação de sentido entre os estudantes. Tais escolhas não se devem a uma vontade principal de mostrar que o trabalho pedagógico ali realizado "deu certo", mas sim a uma intenção de compartilhar que é possível integrar as tecnologias na aula de 
línguas estrangeiras/adicionais de modo a aproveitar a funcionalidade de seus recursos - ou mesmo desviando/adaptando seus potenciais, para a realização de práticas de aprendizagem significativas, situadas, que nos levam além do que é possível fazer na sala de aula presencial.

Nesse sentido, parece-me proveitoso olhar para esse cenário de mudança desde duas perspectivas: a crítica, e a perspectiva da oportunidade. A perspectiva crítica convida ao olhar interno sobre a aula, não para elencar práticas exitosas ou ineficazes para a aprendizagem, mas sim, no sentido em que argumenta Selwyn (2017), para avaliar o que realmente acontece na aula mediada pela tecnologia digital, e apontar caminhos e estratégias alternativas que justifiquem seu uso. Para o pesquisador, estudos críticos sobre tecnologia e educação deveriam, idealmente, propor "diferentes usos da tecnologia", e portanto, "devem buscar desenvolver e apresentar um "caso convincente" de como e por que a tecnologia deve ter um lugar na educação" (SELWYN, 2017, p 21, citando KONSTANTINOU, 2016; destaques do autor). Os diferentes usos da tecnologia podem se organizar, segundo Selwyn (2017), em torno da pergunta sobre como fazer as coisas serem diferentes, identificando nos espaços online oportunidades para a resistência e a mudança. Nesse sentido, e compreendendo que a tecnologia tem lugar certo na educação pós-pandemia, parece-me oportuno fazer do online um espaço de transgressão de nossas práticas de ensino.

A postura crítica me faz pensar, ao final da escrita deste texto, que o descrito acima nos convida a olhar a tecnologia desde outra perspectiva: talvez não se trate de usos tão inovadores da tecnologia, se considerada apenas por seu lado técnico, mas, sim, trata-se de uma abordagem pedagógica e metodológica diferente do espaço de conversa online do que, acredito, se possa fazer uma disciplina de morfossintaxe do francês na educação online.

O ambiente deste ano estava bem desfavorável, mas no meio da pandemia que atravessamos, o curso de morfossintaxe foi uma boa surpresa. $\mathrm{O}$ conteúdo foi dado de maneira bem interativa, foi nesse curso que eu mais explorei as funcionalidades da plataforma Teams. ${ }^{11}$ (Narrativa de Débora, dezembro 2020)

11. Do original: L'environnement de cette année était vraiment défavorable, mais au milieu de la pandémie que nous traversons, le cours de morphosyntaxe a été une bonne surprise. [...] Le contenu a été donné de manière très interactive, c'est dans ce cours que j'ai le plus exploré les fonctionnalités de la plateforme Teams. 
Outro ponto positivo foi que a professora criou um espaço em que mesmo no a distância e mesmo sem conhecer os colegas (eu não os conhecia) a gente pôde interagir o máximo possível, ao ponto de sentir que eu os conheço um pouco agora. Foi uma experiência mais próxima do presencial para mim. ${ }^{12}$ (Narrativa de Maya, dezembro de 2020)

O momento é de mudança, e por essa razão, propício à reflexão. Ao discutir novas e necessárias formas de viver e de conviver, de produzir e de consumir, a fim de não emendarmos uma pandemia à seguinte, Boaventura Santos (2020) insiste no caráter adaptativo dos seres humanos, ao mesmo tempo que pondera sobre a dificuldade de nos mantermos focados em alternativas no período pós-pandêmico, movidos pelo ilusório retorno ao que era antes.

O período de ensino remoto emergencial, apesar de nos ter colocado, inicialmente, diante de uma série de dificuldades pedagógicas e metodológicas, tem sido rico em nos apontar caminhos alternativos para a educação. Pouco sabemos ainda sobre como (ou quando, para muitas instituições de ensino) será a volta à sala de aula física, ou por quanto tempo ainda permaneceremos conectados à aula online, seja em modalidade totalmente remota ou em uma modalidade híbrida - o que, acredito, fará parte da nossa realidade educacional pós-pandemia.

Talvez essa nova realidade (que nem de longe poderíamos nos habituar a chamar de "novo normal"), se for híbrida na educação, dê os seus primeiros passos na universidade. Por isso, concordo com Moreira e Schlemmer (2020) sobre a necessidade e a urgência das reflexões sobre tecnologia e educação para passarmos a uma educação online e digital de qualidade, moldada pelos aprendizados do período remoto emergencial. Que essa seja a nossa realidade também na educação em línguas estrangeiras/adicionais.

12. Do original: Un autre point positif c'est que la professeure à crée un espace où même dans le distanciel et même sans connaître les collègues (moi je ne les connaissais pas) on a pu échanger le plus possible au point de sentir que je les connais un petit peu maintenant. Il a été une expérience plus proche du présenciel pour moi. 


\section{Conflito de interesses}

A autora declara não ter qualquer conflito de interesse, em potencial, neste estudo e assume responsabilidade total pelo conteúdo do artigo.

\section{Contribuição dos autores}

Eu, Maria del Carmen de la Torre Aranda, declaro, para os devidos fins, que não tenho qualquer conflito de interesse, em potencial, neste estudo. Eu desenvolvi os conceitos e as reflexões de base teórica, a partir de leitura dos textos (artigos e livros) referendados de domínio público registradas nas referências do artigo, como também todos os procedimentos metodológicos relatados e discutidos à luz das teorias de base. Portanto aprovo a versão final do manuscrito e sou responsável por todos os aspectos, incluindo a garantia de sua veracidade e integridade.

\section{Referências}

Bakhtin, M. M. (2010/1979). A estética da criação verbal. Tradução do russo: Paulo Bezerra. São Paulo: Martins Fontes.

Barton, D., LEE, C. (2015). Linguagem online: textos e práticas digitais. São Paulo: Parábola.

Braga, D. B. (2007). Práticas letradas digitais: considerações sobre possibilidades de ensino e reflexão social crítica. In: Araújo, J. C. (Org.). Internet \& ensino: novos gêneros, outros desafios (p. 181195). Rio de Janeiro: Lucerna.

. (2013). Ambientes digitais: Reflexões teóricas e práticas. São Paulo: Cortez.

Leffa, V. J., Irala, V. B. (2014). O ensino de outra(s) língua(s) na contemporaneidade: questões conceituais e metodológicas. In: Leffa, V. J., Irala, V. B. (Org.). Uma espiadinha na sala de aula: ensinando linguas adicionais no Brasil (p. 21-48). Pelotas: Educat. Disponível em: <https://leffa.pro.br/textos/trabalhos/livro_espiadinha.pdf $>$. Acesso: 04 ago. 2021.

Moreira, J. A., Schlemmer, E. (2020). Por um conceito e paradigma de educação digital onlife. Revista UFG, 20, 2-22. https://doi. org/10.5216/revufg.v20.63438. Acesso em 04 ago. 2021.

Ribas, F. C., Tagata, W. M. (2015). A plataforma Moodle na pós-graduação: duas experiências de uso de fóruns de discussão. In: Jesus, D. M. de, Maciel, R. F. (Orgs.). Olhares sobre tecnologias digitais: linguagens, ensino, formação e prática docente (p. 355-381). Campinas: Pontes. 
Santos, B. S. (2020). A cruel pedagogia do vírus. Coimbra: Edições Almedina.

Santos, E. O., Carvalho, F. S. P., Pimentel, M. (2016). Mediação docente online para colaboração: notas de uma pesquisa-formação na cibercultura. ETD - Educação Temática Digital, 18 (1), 23-42. DOI: https://doi.org/10.20396/etd.v18i1.8640749. Acesso em 04 ago. 2021.

Selwyn, N. (2017). Um panorama dos estudos críticos em educação e tecnologias digitais. In: Rocha, C. H., El Kadri, M. S., Windle, J. A. (Orgs.). Diálogos sobre tecnologia educacional: Educação linguística, mobilidade e práticas translíngues (p. 15-40). Campinas: Pontes.

Warschauer, M. (1997). Computer-mediated collaborative learning: theory and practice. The Modern Language Journal, 81 (4), 470481. Special Issue: Interaction, Collaboration, and Cooperation: Learning Languages and Preparing Language Teachers. https://doi. org/10.2307/328890. Acesso em 22 jul. 2021.

Zourou, K. (2007). Paradigme(s) émergent(s) autour des apprentissages collectifs médiatisés en langues, Alsic, 10 (2), 3-26. DOI: https://doi. org/10.4000/alsic.688. Acesso em 4 ago. 2021.

Recebido em: 04/09/2021

Aprovado em: 12/10/2021 